\title{
Multiple Mucosal Bridge Formation in the Esophagus in a Patient with Crohn's Disease
}

Esophageal mucosal bridge formation is a very rare condition that can be caused by congenital anomalies (1), reflux esophagitis (2), mediastinal radiation therapy (3), ingestion of a corrosive agent (3), esophageal monilioma (4), and injury from a nasoenteric feeding tube (5). We present here an unusual case of multiple mucosal bridge formation observed in the esophagus of a patient with Crohn's disease.

A 34-year-old woman presented with diarrhea, lower abdominal pain, aphthous stomatitis, and erosions of the vulva. Radiographic and endoscopic examinations of the intestine revealed linear ulcers in the terminal ileum and cecum, an ileocecal fistula, shortening and tubulation of the ascending and transverse colon, numerous inflammatory polyps in the ascending and transverse colon, and also cobblestone mucosa, ulcerations, fissures, and stricture of the rectum. Esophagography (Figure 1) and esophagoscopy (Figure 2a) revealed multiple mucosal bridges (more than 15) in the mid-esophagus and distal esophagus. Most of the mucosal bridges linked the anterior and posterior walls transversely across the lumen, and a few of them were located longitudinally. The surface of the mucosal bridges, as well as the surrounding mucosa, appeared to be almost smooth, but several healed ulcer scars were found
(Figure 2a). Esophagoscopy on another occasion revealed aphthous ulcers disseminated in the esophagus (Figure 2b). Biopsies from the terminal ileum, colon, rectum, and esophagus revealed inflammatory changes, with no granuloma. She was diagnosed as having Crohn's disease involving the esophagus as well as the small and large intestine.

Since she later suffered from severe anal fistulas and rectal cancer (at 41 years of age), surgical resection was performed. As she had only slight dysphagia attributable to the mucosal bridges, no invasive therapy was given for them. There was no predisposing cause for the mucosal bridges in our patient (1-5), and the inflammatory process of Crohn's disease may therefore have contributed to their formation.

S. Honda', K. Sugimoto', H. Iwasaki', R. Higuchi', H. Kubota', F. Watanabe', S. Yoshii ${ }^{2}$, H. Hanai ${ }^{2}$, E. Kaneko ${ }^{2}$

' Dept. of Gastroenterology,

Fujieda Municipal General Hospital, Fujieda, Japan

${ }^{2}$ First Dept. of Medicine, Hamamatsu University School of Medicine, Hamamatsu, Japan 

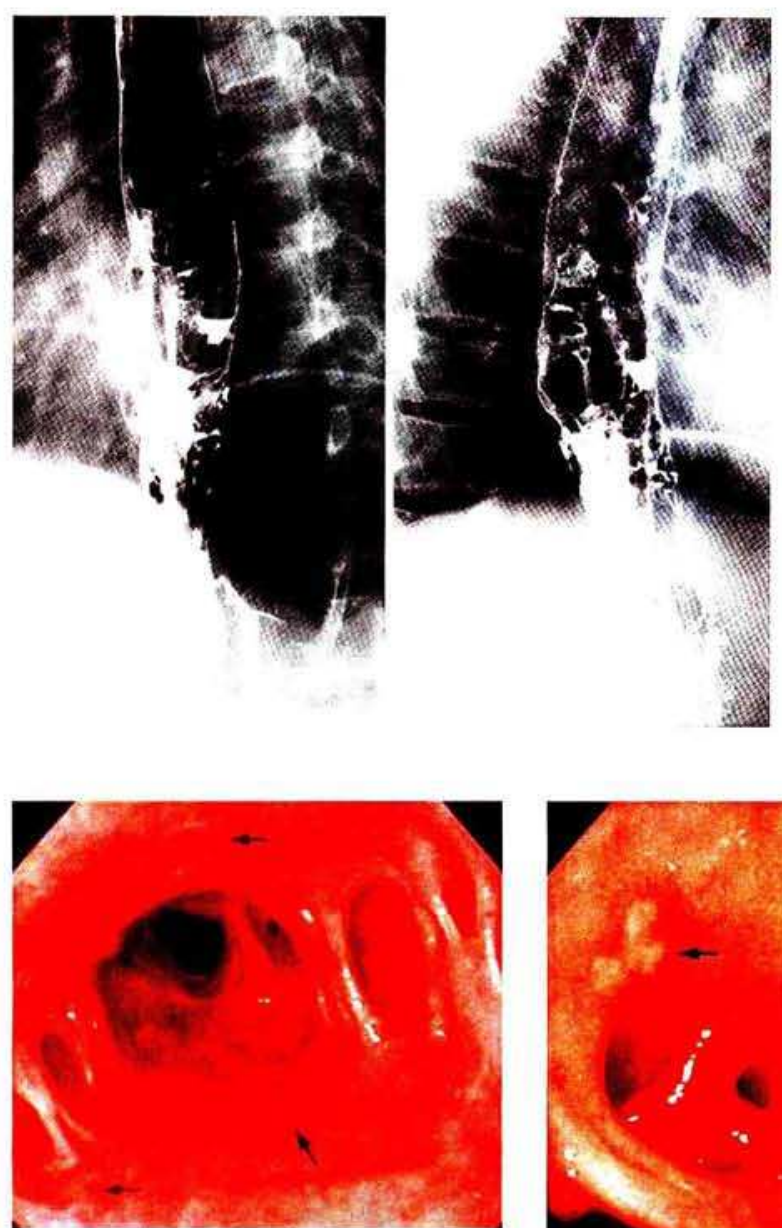

Figure 2a: Endoscopic view of the mid-esophagus, showing multiple mucosal bridges and several healed scars (arrows)
Figure 1: Esophagograms, showing multiple mucosal bridge formation in the midesophagus and distal esophagus.

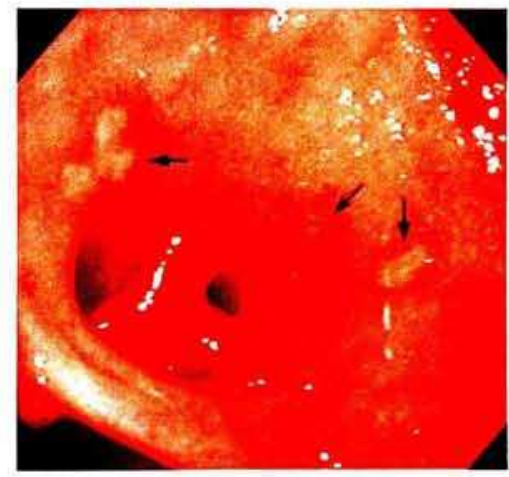

Figure $2 \mathrm{~b}$ : Endoscopic view of the mid-esophagus, showing aphthous ulcers (arrows) around the mucosal bridges.

\section{References}

1. Chang FY, Lai KH, Lee SD, Tsai YT. Asymptomatic mucosal bridge of the upper esophagus. Gastrointest Endosc $1989 ; 35: 472-3$.

2. Papazian A, Capron JP, Sevenet F. Mucosal bridges of the distal esophagus related to reflux esophagitis. Gastrointest Endosc 1984; 30: 217-8.

3. Mohandas KM, Swaroop VS, lyer G et al. Mucosal bridge of the esophagus. Am J Gastroenterol 1990; 85: 907-8.

4. Rattan J, Hallak A, Rozen P et al. Esophageal monilioma and mucosal bridge. Gastrointest Endosc 1982; 28: $114-5$.

5. Buchman AL, Waring JP. Mucosal bridge formation in the esophagus caused by injury from a nasoenteric feeding tube. J Parenter Enter Nutr 1994; $18: 278-9$.

Corresponding Author

S. Honda, M.D.

Dept. of Gastroenterology

Fujieda Municipal General Hospital

4-1-11 Surugadai

Fujieda

Shizuoka 426

Japan

Fax: + 81-54-646-11 14 